$10-2012$

\title{
Turning Counseling Students into Researchers: Enhancing Quantitative Research Courses with an Experiential Learning Activity
}

Mark C. Rehfuss

Old Dominion University, mrehfuss@odu.edu

Dixie D. Meyer

Follow this and additional works at: https://digitalcommons.odu.edu/chs_pubs

Part of the Counseling Commons, and the Educational Methods Commons

\section{Repository Citation}

Rehfuss, Mark C. and Meyer, Dixie D., "Turning Counseling Students into Researchers: Enhancing Quantitative Research Courses with an Experiential Learning Activity" (2012). Counseling \& Human Services Faculty Publications. 6.

https://digitalcommons.odu.edu/chs_pubs/6

\section{Original Publication Citation}

Rehfuss, M. C., \& Meyer, D. D. (2012). Turning counseling students into researchers: Enhancing quantitative research courses with an experiential learning activity. Journal of Counselor Preparation and Supervision, 4(2), 53-65. doi: 10.7729/42.0008 


\title{
Turning Counseling Students into Researchers: Enhancing Quantitative Research Courses with an Experiential Learning Activity
}

\author{
Mark C. Rehfuss \& Dixie D. Meyer
}

Research methods and application are crucial aspects of most counseling practitioners and scholars' lives, yet practical experience with development and implementation of research projects is usually limited to doctoral level dissertations. This article describes an experiential research project that has been integrated into counseling research methods courses at both the master's level and the doctoral level. In this mentored research activity, students move through the entire research process in one semester. They begin with a notion and finish with a submission for publication. Based on student responses, implementing this process in a research methodology course is recommended.

Keywords: pedagogy, research methods, experiential methods, counseling competencies

Sound research plays a foundational role in the practice of counseling and in the scholarship and pedagogy of counselor educators (CACREP, 2009; Huber \& Savage, 2009). The 2009 Council for Accreditation of Counseling and Related Educational Programs Standards (CACREP) Standards clearly delineate that counseling students' outcomes must demonstrate knowledge and application of research methods (CACREP) even if it is one of the more difficult areas for them (Gravetter \& Forzano, 2009). Yet practical experience with development and implementation of research studies is usually limited to doctoral level dissertations. If confidence in evaluating and producing research is crucial to the development of our profession as indicated by CACREP (2009), then research methods courses must do more to engage students in higher order thinking about research in a manner consistent with
Bloom's taxonomy (Anderson \& Krathwohl, 2001; Bloom, Engelhart, Furst, Hiss, \& Krathwohl, 1956). Counselor educators continually have encouraged engagement with research and some educators have even suggested integration of research throughout the curriculum of master's level counseling programs (Huber \& Savage, 2009).

Though knowledge of research methods is crucial to counselor training, little literature has examined or addressed how this training is most effectively accomplished. Recent research has explored challenges in doctoral research training of current counselor educators, concluding that better quality training in quantitative methods, more exposure to qualitative methods, and more direct mentoring by faculty would be helpful (Astramovich, Atiento Okech, \& Hoskins, 2004; Atiento Okech et al., 2006). Huber and Savage (2009) recently discussed how to promote 
research as a core value in master's level counselor training and provided an example of an action research project used to facilitate student discussion and reflection in an ethics course. Such action research projects have been encouraged as a means of integrating research and practice within counseling for many years (Huber \& Savage, 2009; Nelson \& Paisley, 2001; Whiston, 1996), but it still appears few research methods courses are using them. It may be helpful if counseling research methods courses at both master's and doctoral levels would do more to assist students in applying their learning by designing, conducting, and publishing research projects other than theses and dissertations. This fuller application of learning is the goal of the described experiential research activity.

Once students possess a researcher's skill set and have experienced a successful research project with close faculty mentoring (Atiento Okech, Astramovich, Johnson, Hoskins, \& Rubel, 2006), integration of research projects into other counseling courses and into counseling practice could naturally follow. The foci of counseling research courses should seek to develop students beyond basic knowledge, understanding, and evaluation of research and towards an integrative application, analysis, and creation of research (Anderson \& Krathwohl, 2001). This article, therefore, describes a core experiential learning activity that has been used for two years in both master's level and doctoral level research methods courses at a small MidAtlantic university. The goal of this activity is to produce counselors who possess a firm understanding and ability to evaluate research and who also demonstrate the ability to synthesize and create new research (Anderson \& Krathwohl, 2001).

A crucial assumption of this activity is Vygotsky's (1978) zone of proximal development. Vygotsky's concept posits that information presented to students for their comprehension should be geared towards something the students would be unable to achieve without the guidance of a teacher. Thus, the information and application of information should be such that it is too advanced for the students to understand on their own, but something that, with assistance, they will be able to comprehend. This approach to education then challenges the students to learn more than what they could master on their own. With the hard work and guidance of the instructor, the students eventually will develop the skills necessary to gain the cognitive ability to complete the assigned tasks without future assistance. With this concept in mind, students completed a group research activity under the continual guidance and support of the faculty. While a large portion of the course grade was given for this group activity, the course still included individual grades for in-class activities, homework, quizzes, exams and handling of presentation questions.

\section{Experiential Learning Activity to Enhance Research Skills}

\section{Framework for the Activity}

The main vehicle for completing the components of the research activity is working in a group. During the very first class, therefore, it is crucial to inform students that the research project will be a group effort requiring equal contributions by each member. All group work involves challenges as groups move through the phases of forming, storming, norming, performing and adjourning (Johnson \& Johnson, 2000; Tuckman, 1956). As they begin their work, it is helpful to remind students of these phases and to communicate that they will be expected to work through 
these challenges together. Research teams of four to six students are formed around counseling interest areas provided by the instructor.

To create clear lines of communication with the instructor and to facilitate effective group work, each group is instructed to choose a leader, co-leader, secretary and schedule/time keeper (Johnson \& Johnson, 2000). The leader serves as the main point of communication between the group and the instructor, the co-leader takes over if the leader is not present, the secretary takes notes on meeting times to make sure objectives are achieved and the scheduler/time keeper makes sure group meetings are scheduled and are productive within the time limits given. The group leader is crucial to the success of the group and to the learning experience (Johnson \& Johnson, 2000). To ensure effective group work in which each student puts forth an equal effort the group work is graded and peer evaluations are used in evaluating each individual's effort within the group.

\section{Peer Evaluation}

Peer critique and evaluation are a constant part of professional life and integrating this perspective into the project helps to develop students' communication abilities and ensures the integrity of the group project. Therefore, there are three peer evaluations built into the course, one taking place every five weeks. Each evaluation is reported to the instructor. It is expected that each student will take this responsibility seriously and view it as an opportunity to learn and grow as a professional. The evaluation allows students to provide and receive feedback on each group member's strengths and weaknesses related to her/his research group work. A peer evaluation worksheet is provided as a guide, but in general students are to identify strengths and weaknesses of each group member as related to the group tasks.

The first two evaluations are processed in an open discussion format with each member verbally sharing their perspectives of their peers openly. These first two evaluative discussions are designed to help address and resolve issues related to the group task before they create barriers to group success. After each feedback discussion, the leader or secretary of each group creates a one-page summary of the feedback given to each student and sends this to the instructor. Then, if needed, the instructor can intervene with the group and specific individuals. However, while it is expected that initially the groups will work in a professional manner to resolve issues on their own, faculty involvement may be necessary at the end of the first group meeting.

The final evaluation takes place in the fifteenth week of the semester when the project is almost complete. The final evaluation is not shared with the group, but confidentially sent directly to the instructor and serves as a motivator for group members to process and resolve issues effectively throughout the semester (McKeachie \& Svinicki, 2006). The students' final peer evaluation can affect their final course grade in one of two ways: if it is positive they receive a positive 5\% for their group work, but if it is negative they can receive up to a negative $15 \%$ for their group work. It is clearly communicated from the first day of the course that being an effective group member is crucial for the success of this project and that equal effort is expected from every student. For the two semesters in which this activity has been integrated into the course, the first evaluations have been found to provide the needed incentive for students to change behaviors and become productive group members by the end of the semester. 


\section{Experiential Research Activity Procedures}

Crucial to the success of this research activity is the instructor's commitment to working with the students in both research and writing. These dual foci must always be in the instructor's mind as the activity requires verbal and written feedback throughout the semester. Having the students work in teams allows the instructor to make a heavier time investment in verbal and written discussion, critique and correction. The goal of this labor is to develop students' understanding of research and to enhance their ability to reflectively evaluate and produce research. As the principle investigator for each study, the instructor must work diligently to ensure the success of each project while also allowing the students to learn by trial and error.

\section{Course Activity}

\section{General Overview}

During the semester, didactic lectures were used to educate the students on types of research design, fundamentals of research, how to conduct studies, how to analyze data, and how to write reports. Throughout the process, students were expected to demonstrate what they were learning. For example, when learning about hypotheses and appropriate research questions, the groups were asked to write their research questions and hypotheses for their study. Following lectures, the instructor helped the students decide on appropriate constructs to measure, potential inventories that measure the identified constructs, target populations, how to reach the designated population, technology for acquiring and storing data, assigning tasks to group members, or other elements of research design. Faculty engagement is crucial throughout the entire research project from facilitating the discussion on research interests to the completion of the final research report.

What follows is the experiential activity organized by weeks. The focus of this delineation is not upon lecture content but upon the activities necessary for an exploratory research project to be successfully initiated and completed within the confines of a single semester.

\section{Week 1}

In the first class of the semester, the students were informed that a major part of the course included conducting a group research study. This made the course challenging as the students would need to complete usual course activities like keeping up with the readings and assignments as well as learning new information, but in addition they were expected to apply that learning to their group research projects.

Therefore class time during week one was utilized to identify and discuss student research interests, access to samples, and possible collaboration with other faculty. Students were expected to divide into groups of four to six individuals by research interest. Through discussion and interaction with the instructor, each group tentatively decided upon a research topic that fell within the expertise or interest of the instructor who served as the principle investigator for each study. At the master's level, the groups used the initial meeting to decide if they wanted to use a qualitative or quantitative approach to their study. At the doctoral level, the activity was part of a quantitative research course, so that methodology was required. 


\section{Weeks 2 to 3}

The second week of class focused on research ethics and multicultural considerations in research design and application. As a part of the process, students constructed a rough draft of a consent form to use in their research project. Students also completed the National Institute of Health (NIH) online research ethics training course and reviewed the Health Insurance Portability and Accountability Act (HIPAA) personal record privacy requirements. Students were required during week three to turn in their NIH certificate of completion and indicate they had read and would abide by NIH and HIPAA standards in conducting their studies. In addition, during week three, each group handed in a worksheet identifying their research topic and main variables as well as the final informed consent form.

When students met in their groups during week two, they were asked to identify potential populations they could access for their exploratory studies, such as individuals in their work or community settings. Unless the students were choosing to research a particular population, students needed to consider how they could collect data from a diverse sample of individuals. Students were asked to consider potential locations to conduct their research study. For example, if they wanted to research counseling interventions, students were asked if they had access to a counseling center, potential counselors willing to include the counseling intervention in practice, and enough clients at the counseling center willing to participate in research. Students also worked to secure permission to conduct a research study at the desired site. By contemplating this information early on, potential sites with barriers could be ruled out and appropriate sites identified and secured. If sites could not be identified other databases were made available to the students to use. In the master's level course, students were informed they could investigate a topic relevant to masters counseling students and were given the option of conducting their exploratory research with participants in the research course.

The focus for week three was learning how to complete a literature review. The assignment for the following week was for each group to identify and submit a written summary of 8-10 research articles related to their study. The summary of each article included identifying the research design, variables studied, instruments utilized, population sampled, and significant findings discovered. Upon reviewing the literature, students also worked with their groups to identify appropriate measures or assessments for collecting their data and possible journals that would be interested in their research reports. The requirement for journal submission was only for the doctoral students, though master's students could submit their reports if appropriate. The final assignment due during this week was a onepage summary proposal for their research study. The required information included a title, selection of a quantitative or qualitative design (master's course only), identified variables to investigate including instruments or another manner to measure the variables, their independent and dependent variables if applicable, the target population, and the location where they planned to conduct the study.

\section{Week 4}

Research design and methodology was the focus of week four. The students decided the type of design their group wanted to implement (e.g., ethnography, survey, experimental), the questions they wanted to answer, and the means of 
collecting their data (e.g., paper and pencil, online, interview). It is crucial that the instructor work closely with the students to achieve a successful design that takes into consideration the limited time frame of the semester and one that does not require a full review by the Institutional Review Board (IRB). The doctoral students must complete their first written outline or very rough draft of their research article this week as well. This typically includes only a brief introduction section, a short literature review and an outline of the rest of the article. To assist with this process, each group was required to identify and provide two research articles with a similar research design from a journal that would be interested in their topic. This allowed the students to see how such a study should be presented and facilitated the effective organization of their reports.

During this week, each student group secured and submitted a site permission letter that indicated the researchers were allowed to use the site to conduct their research study. This is one point where students' plans can significantly go astray. Though site access may have been assured, students may find it difficult to secure site authorization and be forced to modify or change their study. The instructor must be ready and willing to deal with such challenges and work with the students to identify another site or create another study option with the students such as using a convenience sample or an existing data set.

\section{Weeks 5 to 6}

Week five focused on developing research hypothesizes and the IRB process. The groups were expected to develop clear and concise research questions and hypotheses. Students were also taught about the importance of the IRB, the requirements for submission, and how to complete the forms for the IRB process. Each group completed the IRB forms for their study and submitted them to the instructor. The instructor served as the principle investigator for the study and needed to review, critique, and return the forms to the students by the end of the week. Each group quickly made the suggested changes and resubmitted the forms to the instructor for a quick approval before the group leader submitted the completed forms to the IRB during the next week. All submissions were copied to the instructor as well. Submission of the IRB forms may need to happen much earlier in the semester depending on the turnaround time of the university's IRB. The university where this course was conducted typically takes one week for exempt reviews.

During week six, the students submitted a second, more detailed rough draft of their article. This draft included a refined introduction, literature review, and methods sections as well as a partial completion of the rest of the segments of an article including participants, results, discussion, limitations and summary. Since the data had not yet been collected, the students could only begin to work on the proposal with the assistance of the instructor. The idea is that students begin to write each section so that the data, once collected and analyzed, can be inserted and the article refined more quickly. This makes the most use of the students' time and shortens the time needed for writing the final article. Some class time during this week was reserved for each group to present and defend their proposed research study. During the presentations the instructor is allowed to call on any of the students to have them describe any part of the research study and they are graded accordingly. 


\section{Weeks 7 to 9}

The seventh week of class or the week after IRB approval, the data collection commenced. Dependent upon the form of the research collection, students entered the field via face-to-face assessments, mailings, or electronic means. Though site approval has been obtained, challenges can still confront students as they begin data collection. Working in teams often meant coordinating schedules and getting all data to a central data enterer. Various sites mean effort must be made to ensure consistent collection methods. In addition, if an online format is used, students may need to allow time for multiple online appeals to gather enough participants to allow for higher level data analysis. It is important to note that depending upon the research study, groups may need to begin data collection prior to week seven. If this is the case, the instructor must work with the group to determine earlier deadlines for IRB submission and the start of data collection.

By the end of week nine all data should be collected and ready for analysis. It is crucial to have all data collected by this time to allow enough time for completion of the article by the end of the semester. During weeks seven through nine, one or two more revisions of each group's article were submitted to the instructor and returned with critique and edits

\section{Weeks 10 to 14}

Weeks 10 through 12 were spent analyzing the data and translating the results for written and oral presentation. At the master's level, the course also includes statistics. However, if the proper analysis is beyond the students' current learning, the instructor can assist the students with analysis or conduct the analysis for the students. Benefits and challenges exist with both options. It would be best to have the students run the simple descriptive statistics and any analyses in which they have been trained (i.e., T tests, Correlations). At the doctoral level, the final analysis should be more advanced and slightly out of the range of the students current learning (i.e., Regressions, MANOVAs, Factor Analysis). Depending on the course progression, many doctoral students may not have had an advanced statistics course, so forming a collaborative partnership with the advanced statistics teacher could prove beneficial for both classes.

In the setting of this course, the firstyear research methods doctoral students only had an elementary exposure to statistics, so the second year doctoral students in advanced statistics served as statistics consultants. The second-year students were grouped into teams and each was assigned to assist one group project. This collaboration provides the second-year students with the opportunity to work together to identify, run, explain, and report a proper statistical analysis for each study. This active collaboration exposes and prepares both groups of students for their dissertations. Weeks 12-14, depending on the timing of data collection, were spent understanding and writing up the results, discussion, and summary of the article. This was then submitted to the instructor for review and critique.

\section{Week 15 to 16}

During week 15, each group presented the results of their study to their peers consistent with the formatting of a dissertation defense for the school or department. This presentation began with an overview of the study, but focused primarily upon the results, limitations and implications for counseling theory, research, and practice. Again, similar to the proposal, 
during the presentations the instructor was allowed to call on any one of the students and have them describe any part of the research study. This presentation also provided a final opportunity for feedback on the study and discussion with faculty and peers, thus, impacting the final article. Peer questions and suggestions focused upon strengthening the discussion section were encouraged. In the final portion of the presentation, each student was required to share their reflections upon the process of learning research methods in this manner. They were to focus upon their experiences in the course and how it impacted them personally and as a team. As a team, they were asked to explore what they learned from the process and what they would do differently when conducting a future research study. The final version of each research article was due to the instructor at the end of week 15 which allowed the instructor one last review before submission to the journal during week 16. Though submission is the goal of the project, not all of the studies produce results that are publishable, and therefore, not all of the reports are submitted for journal review.

\section{Challenges}

Several barriers could arise in implementing this activity and faculty and students should be aware of these before integrating and conducting a similar exercise. First, in order for this type of core experiential activity to be successful, deadlines must be set and enforced throughout the semester (Schunk \& Zimmerman, 2003). This helps the students maintain momentum so that execution, completion, and summarization of the study can be completed by the end of the semester. At midterm, for example, the students were expected to have designed their research methodology, begun data collection, and to have written the introduction, literature review, and methodology of their research report. Second, time for research project application and general discussion happened before, during, and after class, but additional course-specific faculty office hours were also offered to the students. Normal office hours were still maintained, but during the course-specific office hours, there was an open door policy whereby all students from the course were welcome to share their concerns and receive more guidance. Because students often struggle with the same issues, all students were encouraged to come and listen to others' concerns and express their concerns. This resulted in multiple questions being answered simultaneously and made the most of the instructor's and students' time. Some of these course-specific office hours were conducted online and a live audio archive of the session was made available so students unable to get to campus could listen and learn from the discussion. The success of this research project activity depends upon the faculty and upon the functioning of the research group.

Group work is the third challenge to this activity as students often have reservations about working in groups, especially when their grades are dependent upon others' work. Some students may think that they can put in less effort and rely on others' strengths to carry the load in a group. It is crucial, therefore, that accountability for performance is a mainstay of this exercise. This has been addressed by the peer evaluations, the weighting of such evaluations upon final grades and by expecting each group member to be able to demonstrate their learning during class presentations (McKeachie \& Svinicki, 2006). However, students must be encouraged to be honest and work through the stages of group work in order to achieve a productive environment that will lead to 
group success (Johnson \& Johnson, 2000; Tuckman, 1965; Tuckman \& Jensen, 1977). If students can be honest with one another and with the instructor, the process should move along smoothly. Such group work often highlights a student's needs and weaknesses that individual work does not. The instructor and peers must, therefore, see this feedback forum as an opportunity for both personal and professional growth and development.

In addition to personal challenges, most challenges with the activity lie in the areas of sampling, meeting deadlines, and analysis. Of primary concern is the need to secure a sample of the population the students want to study before moving too far along in the process of the research design. Given the short time frame to design and to conduct the study, it is imperative that the instructor or the students have access to a sample of individuals consistent with the study. Using existing government data sets or existing data sets of faculty limits the research questions but can facilitate the research process. Furthermore, it is important to make sure students adhere to the deadlines and that all groups remain on target to reach each of the goals for the project. If any of the groups get behind, it may be difficult for the group to complete the project during the semester. Therefore, the instructor will need to check in with each group regularly to make sure all goals and deadlines are met. A final problem to address is if data analysis results in no significant findings. When this happens, which it will, it is best to help the students to process the data and write it up "as if" for publication. In their write-up, they should address why they think their hypothesis was wrong and describe how future studies could be strengthened to more fully explore their constructs.

Students often come into research courses concerned about their ability to perform well, therefore, learning on the first day that they will be executing their own research study may increase their level of trepidation. It is crucial then that the instructor articulates that his or her primary role is to actively guide the students through the entire research project. The instructor will work hard to facilitate their learning about the research process by helping and guiding them to immediately apply their leaning. Instructors must openly acknowledge that to complete a research project and write the research report in the same semester is a tremendous challenge. It requires both the instructor and the students to be consistently engaged with the projects. Therefore, it is important to use class time for application, to clearly articulate the expectations of the students early in the semester, and to check in with each group weekly to make sure they understand and are completing each expected task. In addition, each step of the research project (e.g. writing research questions, number of participants, analysis of data) is given as a graded homework assignment to ensure timely completion.

\section{Student Evaluations}

When presenting any type of learning activity as an example, some form of evaluation of the effectiveness of the technique should be included. Although this evaluation is not exhaustive and is only descriptive in manner, it represents an attempt to highlight the effect of the activity from the students' perspectives. Two classes of doctoral level counseling students and two classes of master's level students participated in this experiential training in research. Three sources formed the textual basis for the students' feedback about the experiential learning activity including their final class evaluations, peer evaluations, and final presentations. 
From the evaluation methods described, students at both levels consistently said that if they could keep one element of the course they would want to keep the research project. Students expressed that, "going through the process of the research project was invaluable," "completing an actual study and writing for publication was very beneficial," and "working as a group on the project needs to be kept." Statements about the most significant learning experience in the course revolved around the project as well: "I felt a sense of accomplishment as we submitted the final manuscript because we had put in a lot of effort as a research group and we were able to put into practice what we had learned in theory;" "My most significant learning experience was the research project. I had never conducted one before and so the whole class was a great learning experience;" and, "What the process of research to publication is like was my most significant learning experience." Students reported finding support in the group work as well with statements such as: "The most significant learning experience was with the group work on the research project;" and, "We have learned to rely on one another for strength, guidance, and support in the areas of researching, writing, and analyzing data, and have grown to appreciate one another on a personal level as well."

The doctoral level students $(\mathrm{N}=20)$ before the start of their course were asked to describe their interest in research methods few described it as high $(\mathrm{n}=3 ; 15 \%)$, most as medium $(\mathrm{n}=10 ; 50 \%)$ and many as low $(\mathrm{n}=7 ; 35 \%)$, while after the course most described it as high $(\mathrm{n}=13 ; 65 \%)$, many as medium $(\mathrm{n}=7 ; 35 \%)$ and none $(0 \%)$ described it as low. A majority of the students $(n=14 ; 70 \%)$ indicated that they learned more in this course than most or any other course, while only a few $(n=6 ; 30 \%)$ felt that their learning was the same as in most other courses. None felt that it was less than other courses. Overall, it appears that the group research projects helped the students to grow and to develop as researchers and as individuals.

\section{Conclusion}

Though this activity appears helpful for these students, several recommendations can be made to improve its effectiveness. When using this exercise or a similar activity, it might be helpful to expand experiential learning by further integrating it with other courses the students are taking or will take in the future. The first time the activity was used in the doctoral level course the students had not completed advanced quantitative statistics and this hampered their ability to conduct appropriate analysis and limited their research designs. The second time the course was taught the instructor partnered with the advanced statistics course instructor and recruited students in that course to serve as statistical consultants for the projects. This benefited both classes as the students in the advanced statistics course also had to immediately apply what they were learning to help their research teams. Such creative thinking and collaboration has the potential to continue to enhance student learning regarding research.

Due to the doctoral level course being a quantitative methods course, only the master's level students were able to use the experience to explore and learn qualitative research. Expanding this type of research activity to a qualitative research course at the doctoral level is strongly suggested. This is consistent with a study of counselor educators in which they indicated they would have liked more training in qualitative research (Atieno Okech et al., 2006). It may prove beneficial to use a similar experiential group activity in a qualitative research course to facilitate the 
training of counselor educators (Reisetter et al., 2004). Working in teams to develop and conduct a qualitative study across the semester would facilitate application and immersion into various qualitative approaches and help to develop the confidence of counselor educators in training.

Modifications to this activity could easily be integrated into other courses for master's students or students with limited exposure to research. A simple modification would be to make the class a research laboratory where the students execute a research project designed by the instructor. If the instructor wanted to investigate multiple constructs and enough variables could be included, the student groups could select variables for their own specific projects within the overarching course research framework. This would allow for easier identification of populations, measures, and create a shared literature for each project. The students would still have the responsibility of conducting a research study, but the research design could be predetermined. In addition, master's students could present results as case reports not fully developed research reports for publication.

Although experiential learning activities can create challenges for instructors and students, such methods are worth the effort. Considering the goal of most research methods courses is to develop competence in research evaluation and application, generating research would seem to be a natural part of the process. More specific research is needed, but engaging students in immediate and consistent application of their learning related to research appears to make it much more tangible, manageable, and invaluable in understanding the research process. By actively engaging students in research methods and research production, it is hoped that students will increase their confidence and engagement in research and begin to view it as a part of a counselor's identity.

http://dx.doi.org/10.7729/42.0008 


\section{References}

Anderson, L. W., \& Krathwohl, D. R. (Eds.). (2001). A taxonomy for learning, teaching, and assessing: A revision of Bloom's taxonomy of educational objectives. New York: Longman.

Astramovich, R. L., Atieno Okech, J. E., \& Hoskins, W. J. (2004). Counsellor educators' perceptions of their doctoral coursework in research methods. Guidance and Counseling, 19(3), 124-131.

Atieno Okech, J. E., Astramovich, R. L., Johnson, M. M., Hoskins, W. J., \& Rubel, D. J. (2006). Doctoral research training of counselor education faculty. Counselor Education \& Supervision, 48, 131-145. http://dx.doi.org/10.1002/j.1556-6978.2006.tb00018.x

Bloom, B. S. (Ed.), Engelhart, M. D., Furst, E. J., Hiss, W. H., \& Krathwohl, D. R. (1956). Taxonomy of education objectives, The classification of educational goals, Handbook I: Cognitive Domain. New York, NY: David McKay Company, Inc.

Council for Accreditation of Counseling and Related Educational Programs. (2009). 2009 Standards. Retrieved from www.cacrep.org

Gravetter, F., \& Forzano, L. (2009). Research methods for the behavioral sciences. (3rd ed.) Belmont, CA: Wadsworth Publishing Company.

Huber, C., H., \& Savage, T. S. (2009). Promoting research as a core value in master's-level counselor education. Counselor Education \& Supervision, 48, 167-178. http://dx.doi.org/10.1002/j.1556-6978.2009.tb00072.x

Johnson, D. W., \& Johnson, F. P. (2000). Joining together: group theory and group skills (7th ed). Allyn and Bacon: Boston, MA

McKeachie, W. J., \& Svinicki, M. (2006). Assessing, testing, and evaluating: Grading is not the most important function. In W. McKeachie \& M. Svinicki (Eds.), McKeachie's Teaching Tips: Strategies, Research, and Theory for College and University Teachers (12th ed.) (pp. 74-86). Belmont, CA: Wadsworth.

Nelson, M. L., \& Paisley, P. O. (2001). Teaching counseling research from a constructivist perspective. In K. Eriksen \& G. McAuliffe (Eds.), Teaching counselors and therapists : Constructivist and developmental course design (pp. 125-137). Westport, CT: Bergin \& Garvey.

Reisetter, M., Korcuska, J. S., Yexley, M., Bonds, D., Nikels, H., \& McHenry, W. (2004). Counselor educators and qualitative research: Affirming a research identity. Counselor Education \& Supervision, 44, 2-16. http://dx.doi.org/10.1002/j.1556-6978.2004.tb01856.x

Schunk, D. H., \& Zimmerman, B. J. (Eds.). (2003). Self-regulated learning: From teaching to self-reflective practice. New York: Guilford.

Tuckman, B. (1965). Developmental sequence in small groups. Psychological Bulletin, 63, 384399.

http://dx.doi.org/10.1037/h0022100

PMid:14314073

Tuckman, B., \& Jensen, M. (1977). Stage of small group development revisited. Group and Organizational Studies, 2, 419-427. http://dx.doi.org/10.1177/105960117700200404

Vygotsky, L. S. (1978). Mind in society: The development of higher psychological processes. Cambridge, MA: Harvard University Press. 


\section{Author Note}

Mark C. Rehfuss, Department of Counseling and Human Services, Old Dominion University, 110 Education Building, Norfolk, VA 23529

Dixie D. Meyer, Department of Counseling and Family Therapy, Saint Louis University, 3500 Lindell Boulevard, Saint Louis, MO 63103

Correspondence concerning this article should be sent to Dixie D. Meyer at dmeyer40@slu.edu 